\title{
Middle-ground pension plan benefit design and pension communication to members
}

Received: 5th May, 2004

\section{Raj Mody}

is a principal consultant with Hewitt Associates and a member of the Hewitt Leadership Group. He advises companies and pension plan trustees on a full range of pensions and benefits issues. He regularly appears on television and radio and was ranked one of the top 50 most influential people in the pensions industry in recent surveys by Professional Pensions magazine. He frequently speaks at key industry conferences.

Abstract This paper looks at emerging ideas underlying new 'middle ground' pension plan benefit designs. Such designs sit on the risk-sharing spectrum between the extremes of final salary and defined contribution. In particular, this paper introduces the concept of a targeted retirement account (TRAC) and examines how this type of design might overcome some of the problems of traditional final salary or defined contribution arrangements. It also looks at the role of member communications in explaining, and improving employee appreciation of, pension arrangements. It considers latest trends in the communication of pension benefits, drawing on lessons from the field of behavioural finance, which can help employees make better decisions about their pension savings.

Keywords: pension plan design; risk-sharing; hybrid; middle-ground; member communication; behavioural finance

\section{The changing landscape of pension design}

The trend in the UK of the shift from final salary plans to defined contribution (DC) plans has been well documented, with specific cases being reported extensively in both trade and national media. Recent surveys confirm the trend. A survey carried out by the Chartered Institute of Personnel and Development (CIPD), ${ }^{1}$ covering 572 organisations, found that more of those employers offer a DC plan to newly recruited employees than provide a defined benefit (DB) plan.
Even for existing staff, only six out of every ten companies still offer access to a DB pension arrangement.

A recent survey by the National Association of Pension Funds (NAPF) ${ }^{2}$ of
464 companies found that, for respondents who had closed final salary plans, seven out of ten said their main reason for doing so was cost containment.

\section{What's wrong with final salary plans?}

When considering the reasons behind the increasing cost of final salary plans, most commentators often focus on current issues. For example, the NAPF survey ${ }^{2}$ notes that

'the current economic climate, over complex legislation and increasing longevity of the workforce have all combined to make it increasingly difficult for employers to 


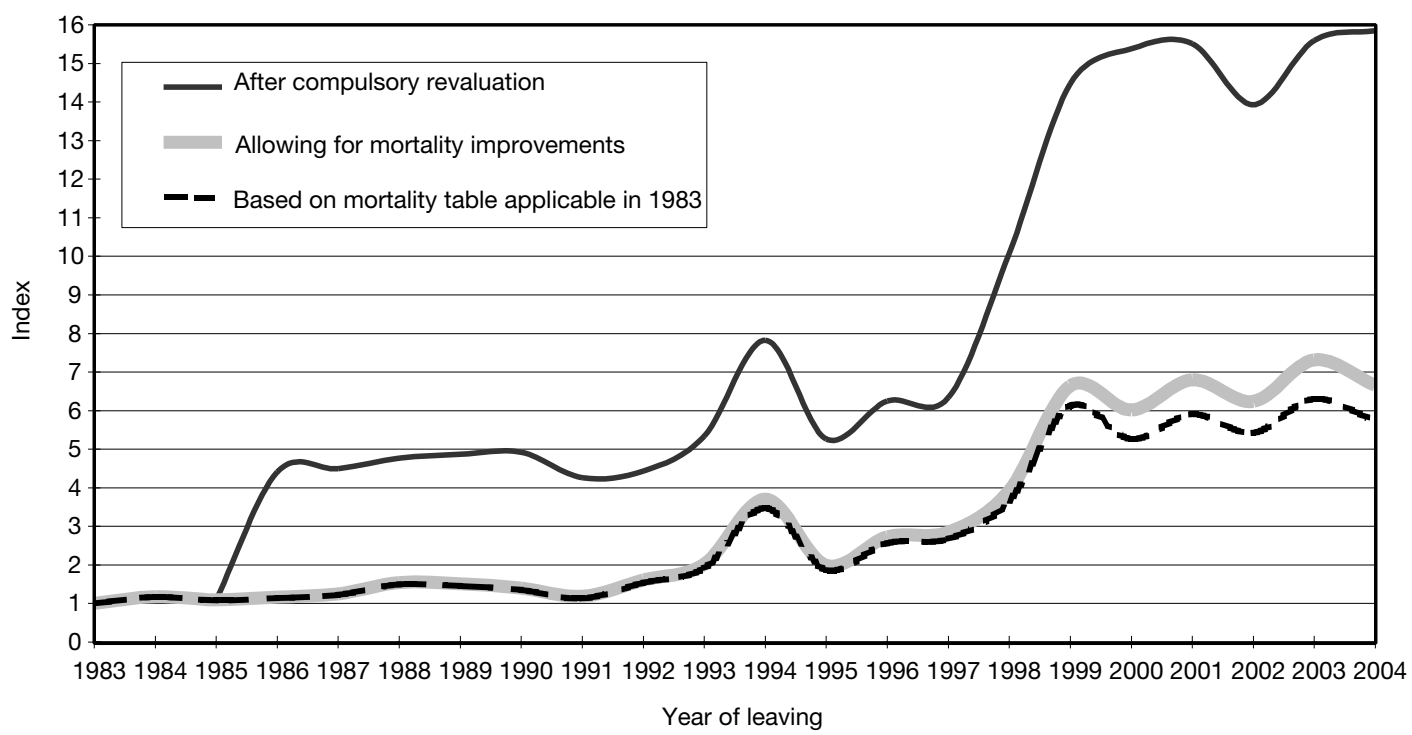

Figure 1: Cost of providing a deferred pension of $£ 1$ pa at age 65 for a male currently aged 45

provide new recruits with membership of final salary pension schemes'.

While these factors are relevant, the analysis in Figure 1 shows that it is the impact of government intervention on pension plan design which has been the biggest instantaneous source of cost increase over the last two decades. Consider the cost of providing an additional $\mathcal{K}_{1} 1$ of pension for a 45-year-old male in a final salary plan, who leaves service to become a deferred pensioner, with a retirement age of 65 . We can look at how this cost would have varied depending on market conditions, longevity expectations and regulatory requirements, in the year this pension was accrued.

The lowest line in the chart tracks the market-related cost without any subsequent index-linking to the accrued pension either before or in retirement. The lack of any increases reflects the minimum statutory requirement prior to 1985. The cost change over time allows only for changes in economic conditions, specifically movements in long-term interest rates. The scale rebases the value at the start of the time period so other values are relative to this level.

The middle line then introduces the effect of increasing longevity, based on prevailing actuarial tables of the time, allowing for future projected improvements considered appropriate at each point.

Finally, the top line introduces the effect of two statutory changes to the level of benefits which had to be provided by final salary plans. In 1985 , the requirement was introduced to increase benefits for a member leaving early broadly in line with price inflation between the point of leaving and retirement (up to a cap of 5 per cent for each year over the whole period).

Then, in 1997, came the requirement to increase pensions in payment earned after 5th April, 1997 in line with price inflation, up to a cap of 5 per cent each year. (A proposal by the Department of Work and Pensions ${ }^{3}$ would reduce this cap to 2.5 per cent each year for benefits earned from April 2005.)

Crucially, these compulsory changes removed a safety valve for sponsoring employers. Prior to 1997, for example, 
companies may well have granted discretionary increases to pensions in payment, but could make this decision taking into account its affordability in context of the overall funding position of the pension plan, and financial strength of the sponsoring company itself.

To exacerbate the problem with final salary plans, the reward from any investment risk the employer supports is asymmetric. If investment risk pays off, this generates a surplus and there is typically pressure to award benefit improvements to members, especially if the sponsor wishes to use part of the surplus to cover an employer contribution holiday. So the sponsor reaps only part of the reward from the investment risk taken. In contrast, if the investment risk does not pay off, this generates a deficit which the sponsor has to make good. There is no scope to reduce members' accrued benefits. Even the possibility of removing or reducing future salary linkage for accrued pensions would be disregarded because of the likely insurmountable employee relations difficulties. The sponsor, while solvent, is committed to make good all the deficit, so bearing all the impact of the investment downside risk.

Although companies choosing voluntarily to provide occupational pension plans cannot insulate themselves entirely from political risk, it would seem desirable for future pension designs to have built-in safety valves to help mitigate costs increasing, and funding strains arising in respect of accrued benefits, as a result of external factors. It would also help if designs do not have such asymmetric risk/reward features.

\section{What's wrong with defined contribution plans?}

The move towards DC plans has achieved the aim of transferring most of the financial risks of final salary plans across to members, particularly the risk of investment, but has far from solved for the employer all of the problems connected with these risks. Arguably, the shift to DC will create new problems, partly because of how individual members react to the impact of certain investment risks.

An individual could be concerned with the level of his projected pension and/or the current size of his DC account. At different stages in his career, an individual may focus on the levels of these two measures or variations in them over time. Given this, we can identify three principal risks with DC plans. They would be:

- Low pension risk: The risk that a period of low investment returns will lead to a low pension amount.

- Mid career volatility: The risk that short periods of relatively extreme negative returns during an individual's working lifetime can create a lack of confidence.

- Pre-retirement market risk: The risk that adverse experience, either from investment performance or annuity costs, close to retirement leads to a member's expectations not being realised.

The nature of a DC plan is that members bear these risks. However, there can be serious HR implications from these risks for companies sponsoring DC plans. For example:

- If members are uneasy about poor investment market conditions, even though they are some way from retirement, this could lead them to make irrational investment selections. It may also affect their morale, productivity, and trust of their employer.

- It may be difficult to encourage 
particular employees no longer needed by the business to retire if they have inadequate pensions - whether resulting from actual poor investment returns, or low saving rates which relied on higher than achieved expected investment returns. This could result in increased business costs through running a higher than necessary payroll, or having to make redundancies.

- If these higher business costs in turn constrain new recruitment, it could lead to a skills gap for the company in future.

- There are problems too in favourable market conditions with DC, when key employees might want to retire earlier than expected because they can afford to, resulting in disruption to the business and urgent, costly recruitment needs.

In practice, once employers develop a full understanding of these issues, they may be less comfortable with passing such pension risks onto members through a DC plan. When companies are considering long-term pensions strategy decisions, it is key that there is a balance between HR and finance functions. In particular, the HR function has a role in helping the finance function appreciate that a move to DC does not offload all the risks associated with occupational pension provision, and in fact creates new risks over time.

Perhaps the most fundamental flaw of DC becomes apparent when we remind ourselves of the main purpose of occupational pension plans - to provide employees with an income in retirement. In many cases, this will be the primary source of retirement income for individuals. Yet it is impossible to predict with any certainty in a DC plan what that level of income will be.

Figure 2 shows the potential variability of a pension from a DC plan. It models the effect of three investment strategies. The bars show the range of pension, as a percentage of final salary at retirement, with the top and bottom 1 per cent of these stochastic projections excluded.

(This is based on a 35 year-old member with total contributions of 8 per cent of earnings each year from age 35 to age 65 , when a single-life annuity with retail price inflation (RPI) increases in payment is bought. The calibration of the asset model underlying these projections includes an expected median equity outperformance over gilts of 3 per cent a year. The projections calculate returns for yearly periods, and assume a rebalancing of asset allocation once a year.)

The underlying investment strategies are as follows:

- The top bar ('aggressive') assumes 100 per cent investment in UK equities.

- The middle bar ('balanced') assumes 50 per cent UK equities and 50 per cent UK fixed interest gilts throughout.

- The bottom bar ('cautious') assumes 10 per cent UK equities and 90 per cent UK linked-gilts.

The graph illustrates that greater certainty can only be achieved at the expense of reducing the median outcome. Greater certainty is defined as a reduction in the variability of potential outcomes for pension amount, so reducing the risk of low absolute levels of pension or a lower pension amount compared to a member's expectation. In effect, we exchange the uncertain but potential extra reward of equity investment with the certainty of lower returns associated with investments such as gilts. The effect of the trade-off is significant in terms of a reduction in the expected outcome, but even the strategy labelled 'cautious' is some way 


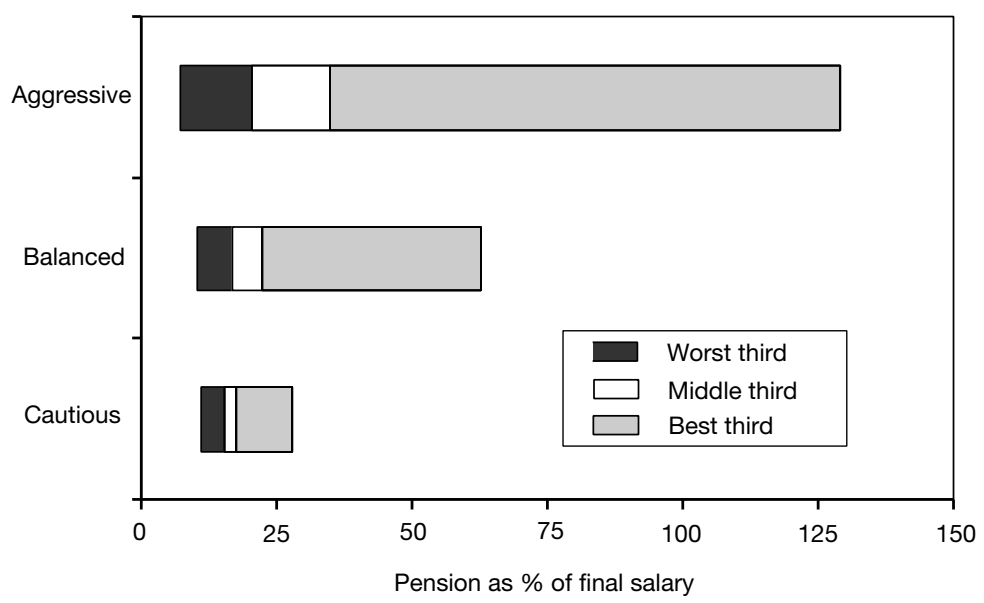

Figure 2: Variability of a DC pension

from assuring a predictable enough outcome which all individuals could rely on for retirement planning.

\section{Finding a middle ground}

Companies are increasingly searching for design solutions which avoid some of the undesirable features of final salary or DC. Before developing such designs, it can be useful to break down familiar pension designs into their constituent features (see Table 1).

For example, for a typical final salary plan, the allocation of benefit each year is some percentage of pay, usually expressed as an accrual rate (such as 1/60). The shape of the benefit granted takes the form of a pension, and the pension accrued each year is increased up to retirement in line with the member's pensionable pay while still in service as an employee, and broadly in with RPI between early leaving and retirement.

A career average plan operates in a similar way but does not provide salary-linked revaluation in service, instead replacing this typically with at least guaranteed RPI. The shape of the benefit granted is still in the form of a pension.

Finally, a DC plan provides a lump sum at retirement, typically used to buy a pension on the open market. This eliminates the risks for the company sponsor which come with committing to provide a pension income for life principally life expectancy and interest rate risks. (There are some occupational pension plan arrangements which allow conversion of the lump sum to a pension within the plan, and sometimes on terms which are more generous for the member than market-neutral.) Increases to the accrued DC benefit up to retirement would be in line with returns on the invested assets, on an individual basis.

We can introduce an alternative 'middle-ground' design, which for the purpose of this paper we will call a targeted retirement account, or TRAC. An outline of how this could work is as follows.

\section{Targeted retirement account}

Up to retirement, a TRAC plan would assign an account to each individual member, as with DC. However, the investment strategy behind the accounts is not at individual members' discretion, but instead under control of the TRAC 
Table 1: Pension designs broken down into constituent features

\begin{tabular}{lllll}
\hline Design & Allocation & Shape & In service & Revaluation \\
& In deferment \\
\hline Final salary & $\%$ of pay & Pension & Pay & RPI \\
Career average & $\%$ of pay & Pension & RPI & RPI \\
Defined contribution & $\%$ of pay & Lump sum & Asset & Asset \\
\hline
\end{tabular}

plan trustees in consultation with the sponsor.

The employer's and employee's contributions are allocated to an individual's account. Then, for example, a TRAC might target RPI revaluations on the account each year up to retirement, but with a guarantee only that the accrued TRAC will not reduce. This gives employers a safety valve in the event of adverse experience for the plan (be it through investment experience or some other external factor) although the intention would be to achieve the target revaluations in normal circumstances. It gives employees better security than with traditional DC plans, with better predictability for projecting their individual TRAC, especially close to retirement.

The employer could vary the revaluation or contribution allocation by individual, linking TRAC awards to factors such as an individual's performance against work objectives, particularly for higher earners and key personnel. This begins to create an explicit link between the pension element of a total reward package and the parameters which govern what an individual's total reward should be.

At retirement, the starting point is the TRAC lump sum, and this could be converted to retirement income with external insurance providers. But the employer can decide in the run-up to an employee's retirement whether to offer in-house income options, depending on the employer's risk tolerance or business needs at the time. For example, the employer could offer 'limited annuities' - income streams for limited periods of three or five years - which are envisaged under new pensions regulations. ${ }^{4}$ Because of the limited term of these income streams, such options do not carry the investment and life expectancy risks for the employer which go with a promise of a conventional pension for life. Crucially, the choice to offer the option and the terms of the option can be decided by the sponsoring company nearer the time of retirement, rather than being set in stone decades before - which is effectively the situation for most current DB designs including final salary and career average.

This overall approach gives greater flexibility and certainty for employees than with a pure DC plan, but with a more controllable risk for the employer, including protection from potential future dramatic improvements in life expectancy.

A TRAC plan can also provide companies with a better distribution of sharing pension risk across their workforce. Companies which currently run closed final salary plans and open DC plans for new recruits, may have two employees doing near identical jobs but with materially different total reward packages because of their pension eligibility. This creates awkward disparity and HR problems. Moving to a middle-ground solution for future accrual across the whole workforce helps to overcome these problems, particularly when an arrangement like TRAC is offered as part of a comprehensive flexible benefits package, when total 
reward measures are clearer for employer and employees. Introducing a

middle-ground solution is a strategy which an employer can adopt without having to increase its overall pension risk exposure - the risk is just spread more evenly across employees, avoiding the polarised outcome from part final salary/part DC coverage.

Employers could in fact choose to operate a TRAC plan on a substantially reduced risk basis. Plan assets can be invested in index-linked gilts or bonds, with returns on these investments being the basis for TRAC account revaluations. There is then limited investment risk for the sponsoring company. TRAC accounts could be supplemented if the company shared its employer National Insurance savings on pension contributions.

For members' extra contributions beyond the core contribution levels available through the TRAC, a pure DC top-up arrangement could be made available. This would operate like current additional voluntary contribution (AVC) arrangements, with market-based conversion of capital to income, but with the additional funds included in an integrated way in a member's accrued and projected benefit statement. This approach, along with the nature of the TRAC principle, also facilitates monitoring and planning against the new Lifetime Allowance tax regime ${ }^{4}$ to be introduced from April 2006.

Figure 3 summarises some of the advantages of TRAC style plans, particularly relative to conventional final salary and DC designs, and especially for employers currently operating a mix of the more traditional plan designs across their workforce.

\section{The incentive for employers}

Companies might question what other incentives they have to bother offering the additional features and flexibility as envisaged under a TRAC plan. The answer lies in an analysis of likely future demographic changes to the profile of the workforce shown in Figure 4.

Over the next 20 years, the total so-called 'working age' population (defined as the number of 18-64 year olds) is projected to increase from around 37 million to just over 38 million, allowing for the increase in female state pension age. But the number of 18-49-year-olds is expected to decrease by 1 million and, over the same period, the number of 50-64-year-olds is expected to increase by 2 million.

This may change the focus for employers in their quest for skilled and talented labour. We may see a shift towards efforts to recruit and retain selected older workers, rather than the current management trend of time and effort being devoted to working out how to reduce headcount at these older ages.

To appeal to these older workers, employers may have to offer more flexible income patterns, including allowing employees to work part-time and draw a partial pension at the same time, and allowing the flexibility for employees to review the balance between work and retirement every few years.

The features of a pension design like TRAC highlighted above, particularly the limited annuity options, may help employers maintain a closer association with their older workforce as they begin their transition to retirement. This may become crucial in the war for scarce talent.

There is some evidence that employers are already beginning to position themselves to react to these developments. The CIPD survey ${ }^{1}$ found that one in six companies had increased retirement ages in the past two years. This is only one small step towards 


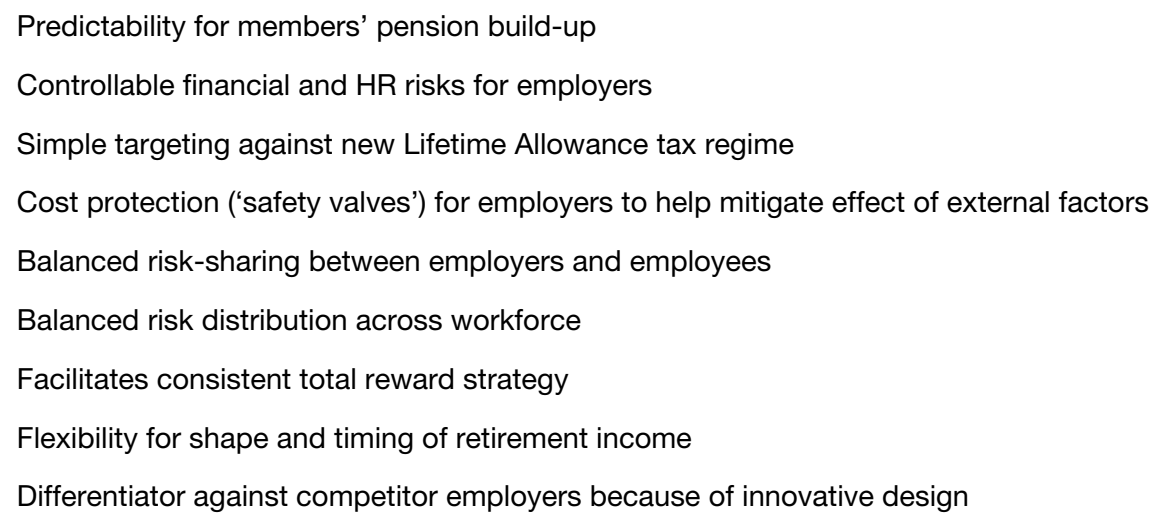

Figure 3: Advantages of TRAC pensions

retention of older workers and the retirement flexibility envisaged under a TRAC-type plan, but still three in ten of these companies cited retaining talent as a reason for making this change. And looking to the next two years, a further one in six of those sampled propose to increase retirement age, with four in every ten of those giving talent retention as an explanation.

Evidence collected by the Select Committee on Economic Affairs ${ }^{5}$ found broad support from various organisations, including the Confederation of British Industry and the Trades Union Congress, for increasing rates of employment among older workers. Increasing participation at older ages is viewed as being consistent with trends in improving life expectancy and health status. It would help meet the current and anticipated demand from employers for more older workers, to balance the anticipated decline in the size of the younger adult workforce. It would also help fulfil the desires of many people in their $50 \mathrm{~s}$ and $60 \mathrm{~s}$ to remain attached to the labour market, though not necessarily on a full-time basis or in their primary occupation.

The Select Committee also found that the government shares this desire to increase employment among older workers, which it regards as 'essential if we are to address the pensions challenge'. Higher participation rates at older ages, and the consequent longer average working lives, help to address the pensions challenge for individuals by increasing the value of their life-time earnings, so increasing the personal resources they have to support themselves in old age.

Implementing a TRAC plan is not without its challenges. But it does seem to provide a compromise to some of the problems of designs which sit at the more extreme ends of the risk-sharing spectrum. It is arguable that any extreme solution (at whichever end, be it final salary or DC) will not be sustainable in the long term. This is because it will be at odds with the collaborative approach required in most cases between employers and employees to achieve an acceptable outcome on pensions, reward or any other employment matter. With more than nine out of ten schemes represented in the National Association of Pension Funds (NAPF) survey ${ }^{2}$ currently either final salary or DC, it seems very likely that we will see yet more change to the occupational pension landscape over the next few years. One challenge will be implementing such change successfully, particularly in 


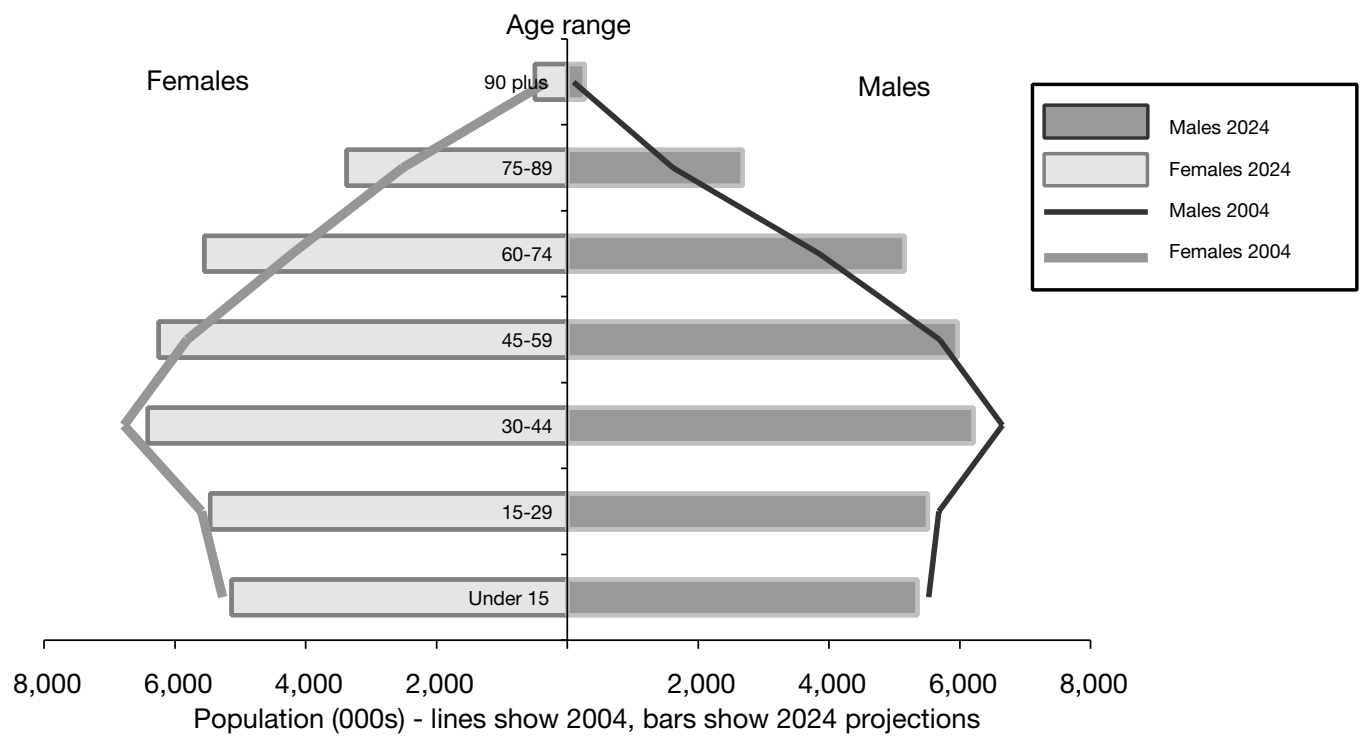

Figure 4: UK population changes 2004-2024

Source: Government Actuary's Department data, December 2003

communicating the changes to employees.

\section{Communicating with members}

Good communication will be key in helping members appreciate the benefits provided by these new pension designs, and the extra flexibility or options offered by their employer.

There is a substantial amount of relevant research from the field of behavioural finance, which observes how human decision making is subject to many kinds of biases and flaws, most of which operate at a subconscious level. A recent article in the Harvard Business Review ${ }^{6}$ summarised the key themes. For example, people naturally give more weight to information that confirms their assumptions and prejudices while dismissing information that would call them into question. We are also creatures of the status quo, drawn to conclusions that justify and perpetuate current conditions, ignoring anything that would create disturbance. And we are particularly influenced by the first information we receive on a particular subject - it becomes, as decision researchers put it, the 'anchor' that determines and distorts how we process all subsequent data.

One of the most dangerous of these behaviours is our deep-seated need to see patterns. Forming patterns is how the brain synthesises information from the past and uses it to understand the present and anticipate the future. But it can get us into trouble. When trying to make a forward-looking decision and when confronted with new phenomena, our brains try to categorise it based on our previous experiences, to fit into one of the patterns stored in our memories. The problem is that, in making that fit we inevitably filter out the very things that make the new phenomena new. Data or information which may be critical in making the most appropriate decision is overlooked, in the rush to recycle our reactions and solutions from the past. This point is revisited later in the context of pension investment decisions. 
Another paper ${ }^{7}$ illustrates further features of our real-life approach to decision making. One experiment asks participants to decide how much they would pay for either of two, used, music dictionaries - Dictionary A with 10,000 entries and as-new condition, or Dictionary B with 20,000 entries and a torn cover but otherwise as-new. Willingness-to-pay was higher for Dictionary B, presumably because of its greater number of entries.

However, when one group of participants evaluated only A and another group evaluated only $\mathrm{B}$, the willingness-to-pay was much higher for Dictionary A. Without a context for comparing the number of entries to decide how good or how bad 10,000 (or $20,000)$ is, people put much more weight on the appearance - regarding a defective dictionary unattractive and a like-new one attractive. We really do, it seems, judge a book by its cover. This tendency to rely on potentially irrelevant information, particularly when it forms part of a first impression, is something which needs to be overcome when communicating pension issues to members.

A more mundane example of this 'less than complete' effect was seen again in an ice-cream experiment. An overfilled small container with 7 ounces of ice-cream was valued more highly (measured by willingness-to-pay) than an underfilled, larger container with 8 ounces of ice-cream, even though participants knew the amounts involved.

It is not a huge leap to see that subtle presentational features of how pension choices are communicated to members could, even inadvertently, lead to inappropriate decisions. Sometimes, the features may not be so subtle and the effect not so inadvertent. Why, for example, do investors unduly rely on past performance and fail to take expected returns as well as risk into account? Two behavioural phenomena may offer some answers. ${ }^{8}$

First, people tend to see patterns in small series of randomly drawn numbers, and attempt to draw conclusions from those patterns. So, investors might identify a fund manager with three years of top performance and conclude that the manager has unusual skill — rather than view it as a random process. But across the universe of hundreds of investment managers, a given manager's three-year track record is just as likely an indication of chance as of skill.

A second issue is that many people tend to rely on readily available information when faced with difficult decisions. A simple reason that investors may rely on past performance could be because that information is cheaply available. Pension plans and investment companies generate prodigious amounts of past performance data which they make available in statements, on websites, in joining materials, and in newsletter updates. Of course, reports on past investment performance are often accompanied by a disclaimer that 'past performance is no guarantee of future results'. Yet you need only to compare the font size of that disclaimer to the font size and volume of past performance data to understand its limitations in the face of this behavioural pattern.

\section{Using lessons from behavioural finance}

For one of Hewitt's internet-based communication tools, Reach, the firm has distilled these and other lessons from behavioural finance to improve member communication and decision making, whatever the type of pension design involved.

For example, the first set of numbers, arguments or conclusions presented will 
be the most memorable. Everything presented subsequently will be judged relative to these, so choose the most relevant and important information to achieve the most impact and avoid distorting decisions. The savings budget in Reach calculates the amount available for long-term retirement saving as a balancing item after monthly outgoings. This is likely to be higher than the amount employees would volunteer to save without this up-front context. It gives them the best outcome for their likely retirement income and they will be reluctant to change the savings levels downwards.

Reach also takes care with the way that options are presented. People tend to read more into the way things are presented than might be expected. They assume that a default option is right for them. They avoid extremes in an ordered list (eg where investment strategies are ranked in terms of risk). They also assume that a long list of options has been ordered in terms of preference - so people tend to choose options which appear early on the list. To avoid these distortions, you can give clues as to which options suit which circumstances. In Reach, when members consider investment options other than the default, they select what to look at by answering a question about risk. They see each option one at a time, with the default as a comparison, rather than showing a whole menu of options.

Developing this theme, bear in mind that individuals find it difficult to make trade-offs, decisions or compromises between many things at a time. So a communication tool should start by raising the issues which are most readily influenced by the reader, most significant, or easiest to grasp. Reach covers 'How much to save?' first, then goes on to look at 'Where to invest?'. If the two decisions are covered at the same time, members will be tempted to save less and take more risk to get the same result, without appreciating that they can control how much they save, but they cannot control the stock market.

In explaining the risk, odds speak louder than probabilities. Natural frequencies are more intuitive and easier for readers to understand properly. As an example, consider the following hypothetical situation and question.

You are at an exhibition marketing hair products. The probability that the next person you meet is completely bald is 1.2 per cent. If that person is completely bald, the probability is 92 per cent that he will be wearing a wig. If a person is not completely bald, the probability is 8 per cent that he will still be wearing a wig. If a person is wearing a wig, what is the probability that he actually is completely bald?

Most people would consider this a complex problem to solve. But we can express the question in another style:

Twelve out of every 1,000 people you meet at the exhibition are completely bald. Of these 12 completely bald people, 11 people will be wearing a wig. Of the remaining 988 people who aren't completely bald, some 80 of them will still be wearing a wig. Imagine a sample of people at the exhibition who are wearing a wig. How many of them are actually completely bald?

More people would probably arrive at the correct answer ${ }^{9}$ through considering the second version of the question instead of the first. Reach shows investment risk as the odds ( $x$ in 100 chance) of not meeting the minimum retirement income selected by the member, rather than using probabilities. It also shows the 50:50 outcome and the one in ten downside outcome as 
these are relatively straightforward for people to understand, and can be brought to life. For example, 'in a room of ten people with the same circumstances as you, one of them will have retirement income lower than this amount - is that a risk you can afford to take?'.

Be careful how charts and ranges are used. When presented with a range of outcomes, people tend to assume that their outcome will be above average. So communication material should use upsides selectively, particularly when it is more important that the implications of downsides are understood. Reach does not have any charts nor does it show the upside outcomes for retirement income projections. This forces members to focus on the risk of not being able to afford to retire at their chosen age.

The CIPD survey ${ }^{1}$ found that the methods most commonly used to communicate information about occupational pension plans are through the recruitment and selection process, the induction process and the staff handbook. These methods are unlikely to be able to be tailored to an individual's particular needs, so will not take into account their financial position and level of understanding. An interactive approach can allow a more tailored path for individuals.

Just under half of the CIPD survey respondents use the staff intranet as a communication medium. There is no data on how many adopt a 'one size fits all' approach or how many offer a more sophisticated solution, such as Reach.

In future, tailored communication, along with innovative and more flexible plan designs, will be essential for a successful approach to delivering occupational pensions.

\section{Acknowledgments}

The author is grateful to the following colleagues at Hewitt Associates for their help and comments during preparation of this paper: Sally Bridgeland, George Carter, Gillian Clark, Andy Cox, Clare Hobro, Colin Mayes, Chris Norden, Steven Vale and Kevin Wesbroom.

\section{References and notes}

1 Third annual survey of UK reward management (2004), Chartered Institute of Personnel and Development. The report also includes definitions of DB and DC plans as follows:

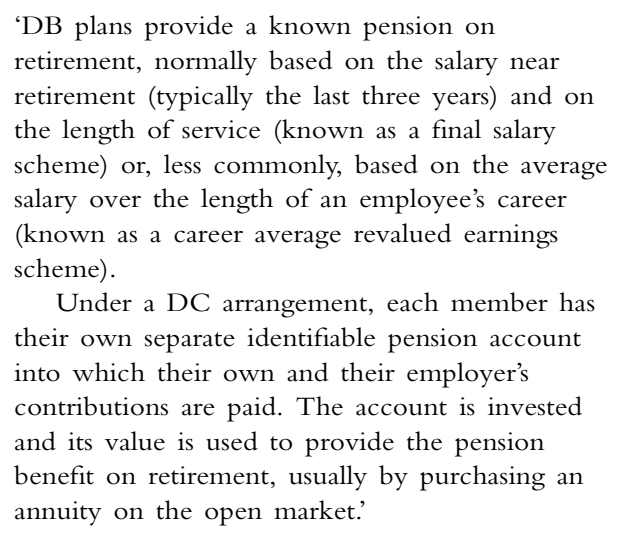
retirement, normally based on the salary near retirement (typically the last three years) and on the length of service (known as a final salary scheme) or, less commonly, based on the average salary over the length of an employee's career (known as a career average revalued earnings scheme)

Under a DC arrangement, each member has their own separate identifiable pension account into which their own and their employer's contributions are paid. The account is invested and its value is used to provide the pension benefit on retirement, usually by purchasing an annuity on the open market.'

2 National Association of Pension Funds (2003) 'Twenty-ninth Annual Survey of Occupational Pension Schemes', NAPF, London.

3 Pensions Bill (April 2004).

4 Inland Revenue (2003) 'Simplifying the taxation of pensions: The Government's proposals', December; HM Treasury Budget (March 2004); Finance Bill (April 2004).

5 Select Committee on Economic Affairs (2003) 'Aspects of the economics of an ageing population', The Stationery Office, November.

6 Bonabeau, E. (2003) 'Don't Trust Your Gut', Harvard Business Review, May.

7 Slovic, P., Peters, E. and MacGregor, D. G. (2002) 'Rational Actors or Rational Fools? Implications of the Affect Heuristic for Behavioural Economics', Decision Research.

8 Mitchell, O. S. and Utkus, S. P. (2003) 'Lessons from Behavioural Finance for Retirement Plan Design', Pensions Research Council Working Paper, Wharton School, University of Pennsylvania, October.

9 Just under one in eight people. 